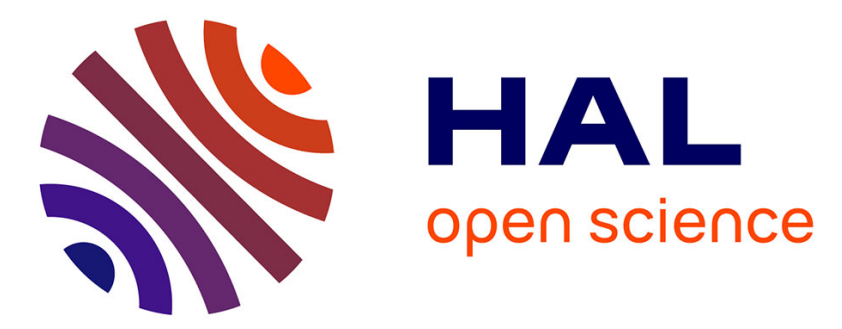

\title{
The genesis, evolution and crisis of an institution: the Protected Designation of Origin in wine markets
}

Christian Barrère

\section{To cite this version:}

Christian Barrère. The genesis, evolution and crisis of an institution: the Protected Designation of Origin in wine markets. Journal of Institutional Economics, 2007, 3 (2), pp.165-181. 10.1017/S1744137407000628 . hal-02615155

\section{HAL Id: hal-02615155 \\ https://hal.science/hal-02615155}

Submitted on 22 May 2020

HAL is a multi-disciplinary open access archive for the deposit and dissemination of scientific research documents, whether they are published or not. The documents may come from teaching and research institutions in France or abroad, or from public or private research centers.
L'archive ouverte pluridisciplinaire HAL, est destinée au dépôt et à la diffusion de documents scientifiques de niveau recherche, publiés ou non, émanant des établissements d'enseignement et de recherche français ou étrangers, des laboratoires publics ou privés. 


\section{Christian Barrère}

Université de Reims Champagne Ardenne

The genesis, evolution and crisis of an institution: The Protected Designation of Origin in wine markets.

\section{in \\ Journal of Institutional Economics 2007, 3(2), pp. 165-181. doi:10.1017/S1744137407000628}




\title{
The genesis, evolution and crisis of an institution: the protected designation of origin in wine markets
}

\author{
Christian Barrère \\ University of Reims
}

\begin{abstract}
This paper addresses a specific institution, the protected designation of origin (PDO) in wine markets. To understand the present strategic choices in the context of the globalization of wine markets, the paper seeks to explain the economic logic of this specific institution, its genesis and its evolution. Using an evolutionary games approach, we build an evolutionary model of the strategic determination of quality. Four configurations emerge. The PDO can be related to signals and policies of quality in strategic situations. This study also yields general results for use in the evolutionary analysis of other institutions.
\end{abstract}

\section{The genesis, evolution and crisis of an institution: the protected designation of origin in wine markets}

\section{Introduction and hypotheses}

The protected designation of origin (PDO) in wine markets (AOC - appellation d'origine contrôlée in France; DOC - denominazione di origine controllata in Italy) is an old institution. Created for the Champagne wine area through a long and disputed process from 1905 to 1935 , it was so successful that it was quickly extended to a number of other geographically located productions in West and South Europe. It proved invulnerable to a long process of privatization. But it still evolves. Today, market shares in wine markets are changing and new producers are appearing. Some leading firms have adapted their strategies. Others, in the old wine countries, have abandoned PDO to develop trademark policies. To 
understand the origins of PDO and the present strategic choices in the context of the globalization of wine markets, this paper seeks to explain the economic logic behind PDO, its genesis, and its evolution. PDO involves signals of quality in strategic situations, when actors compete through diverse strategies.

\section{The framework: an institutionalist and evolutionary analysis of the market}

An appropriate Weberian 'ideal-type' is used here to understand the different possible market configurations and diverse evolutionary paths, and to connect them to some specific determinants. Consequently, we can understand the role of institutions as the upholders of PDO in the organization and management of market configurations. This method is not inductive, because, as Max Weber (1949) argued, reality is characterized by infinite complexity (and the wine world is actually very complex). We focus on the theoretical problem of the definition of quality strategies and the determination of a quality equilibrium. On wine markets, producers can choose strategically between high and low quality, but with what results? To answer this question, we use a theoretical-deductive approach, building a general model of quality determination. This allows us to establish that four configurations are theoretically possible and to study their properties in the contexts of homogeneous and heterogeneous producers. The model can also be used to throw light on how strategies evolved over time in some countries or wine areas. However, as we are limited by space in this paper, the model will only be used as a guide. In some cases our hypotheses are not relevant, for instance when the ranking of payoffs does not correspond to a symmetric game. In others, the model can be a useful tool for institutionalist analysis. In particular, it highlights the historical emergence of the PDO system at the beginning of the twentieth century.

Evolutionary game theory addresses evolutionarily stable equilibria (ESE) and situations in which all the players use pure or mixed evolutionarily stable strategies (ESS) that are resistant to any invasion of an alternative strategy (Weibull, 1995). It assumes that strategies that improve pay-offs are generally preferred by the players; it does not require any strong hypothesis on substantive rationality, as in ordinary games, and it may include the entry of new players with new strategies, strategic mutations, mistakes, learning and weak or bounded rationality (Hargreaves and Varoufakis, 1995). 


\section{The evolutionary equilibrium approach}

In evolutionary game theory, an equilibrium is represented by sets in which all the players use evolutionarily stable strategies. If the strategy is evolutionarily stable, in a given population, that means that it gives a higher payoff, in any case of invasion, than any mutant strategy. By calling $\varepsilon$ the percentage of the mutant population, $\varepsilon \in(0,1)$, I the evolutionarily stable strategy (pure or mixed) and $\mathrm{J}$ the mutant strategy, we have:

$$
\mathrm{E}\{\mathrm{G}(\mathrm{I}, \varepsilon \mathrm{J}+(1-\varepsilon) \mathrm{I})\}>\mathrm{E}\{\mathrm{G}(\mathrm{J}, \varepsilon \mathrm{J}+(1-\varepsilon) \mathrm{I})\} .
$$

A strategy $\mathrm{I}$ is evolutionarily stable if this inequality is true for any strategy $\mathrm{J} \neq \mathrm{I}$. Theory shows that a strategy can be described as evolutionarily stable if, according to an invasion of a different strategy $\mathrm{J}$, for any player $\mathrm{I}=\{1, . . \mathrm{N}\}$ and $\forall \mathrm{J} \subset\{\mathrm{S}\}$, strategies set, the following conditions are together true:

$$
\begin{aligned}
& \text { (1) } \mathrm{E}\{\mathrm{Gi}(\mathrm{I}, \mathrm{I})\} \geq \mathrm{E}\{\mathrm{Gi}(\mathrm{J}, \mathrm{I})\} \\
& \text { (2) or }(2 \mathrm{a}) \text { is true or }(2 \mathrm{~b}) \text { is true } \\
& \text { (2a) } \mathrm{E}\{\mathrm{Gi}(\mathrm{I}, \mathrm{I})\}>\mathrm{E}\{\mathrm{Gi}(\mathrm{J}, \mathrm{I})\} \\
& \text { (2b) } \mathrm{E}\{\mathrm{Gi}(\mathrm{I}, \mathrm{J})\}>\mathrm{E}\{\mathrm{Gi}(\mathrm{J}, \mathrm{J})\}
\end{aligned}
$$

Thus, we can define evolutionarily stable strategies (ESS) and an evolutionarily stable equilibrium (ESE). In a homogeneous population, the ESE will correspond to the adoption by all the players of an evolutionarily stable strategy (pure or mixed), while in heterogeneous populations (polymorphic) they will correspond to a given and stable distribution of the sub-groups, each one playing a strategy.

Dynamic games assume that strategies with superior pay-offs are generally preferred by the players. There is normally a replication mechanism that associates the variation in the proportion of players using a particular strategy and the difference between the pay-off from this strategy and the average pay-off obtained by the other strategies. The set of strategies is composed of all mixed strategies founded on two pure strategies, $\mathrm{S} 1$ and $\mathrm{S} 2$. We use a typical mechanism where qi is the proportion of the players choosing strategy $\mathrm{I}$, and dqi/dt $=$ qi. $[\mathrm{G}(\mathrm{I}, \mathrm{S})-\mathrm{G}(\mathrm{S}, \mathrm{S})], \mathrm{S}$ being any general strategy of the type $[\mathrm{pS} 1,(1-\mathrm{p}) \mathrm{S} 2], 0$ $\leq \mathrm{p} \leq 1$.

The evolutionary games approach is useful because it does not need any strong hypothesis of substantive rationality, as in ordinary games. The game selects ex post winning strategies and these are not necessarily optimal. Players have only to observe the strategic payoffs and adopt the best strategies through an evolutionary process. 
A general evolutionary model of strategic determination of quality is outlined in the following section. Four configurations emerge. The first leads to a high quality equilibrium and a connected path typical of connoisseurs' markets (Section 3). Two others lead to inferior equilibria and low quality markets (Section 4). A third path is based on an institutional organization of markets through the PDO (Section 5). The last configuration is more complex with diverse equilibria and diverse paths (Section 6). We briefly analyse the consequences of the present changes on the institutional organization of wine markets in Section 7.

\section{A general evolutionary model of strategic determination of quality}

Quality is the outcome of the dialectic of strategic choices made by many players. Each producer chooses either a high or a low level of quality (the pure strategies of the game), or an intermediate level (mixed game strategies). The pure strategy of high quality is noted $\mathrm{h}$ for players (1) and $\mathrm{H}$ for players (2), whereas the pure strategy of low quality is noted 1 for players (1) and L for players (2). The game is in a standard and normalized form: 


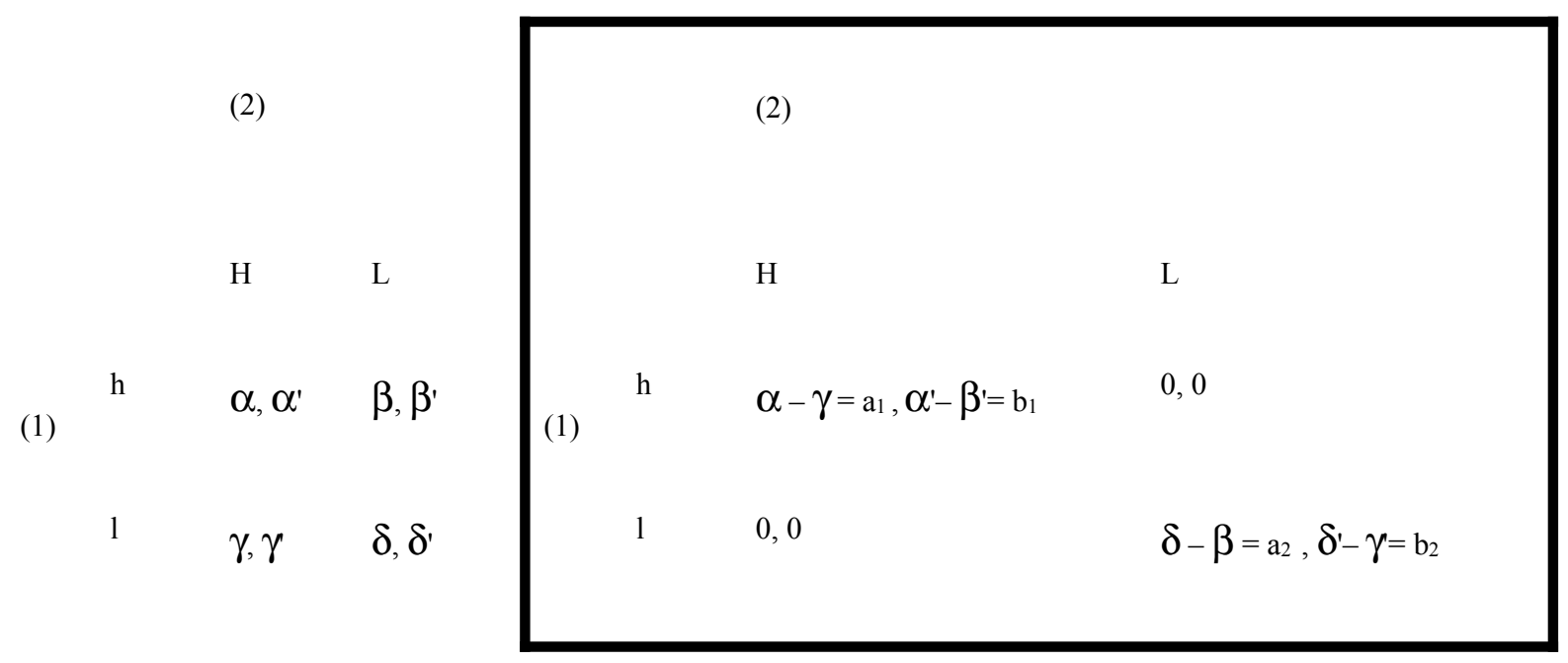

$a_{1}$ represents the difference in payoff for players (1) when they reply to the $H$ strategy of players (2) by $\mathrm{h}$ instead of 1 ; $\mathrm{a}_{2}$ the difference in payoff for players (1) when they reply to the L strategy of players (2) by 1 instead of $h$; $b_{1}$ the difference in payoff for players (2) when they reply to the h strategy of players (1) by $\mathrm{H}$ instead of $\mathrm{L}$; $\mathrm{b}_{2}$ the difference in payoff for players (2) when they reply to the 1 strategy of players (1) by L instead of $\mathrm{H}$.

If the structure of the payoffs is the same, that is to say if the range of payoffs is the same for $\alpha, \beta, \gamma, \delta$ and for $\alpha^{\prime}, \beta^{\prime}, \gamma^{\prime}, \delta^{\prime}$, the game becomes a symmetric one, with $a_{1}=x_{1}$, $a_{2}=y b_{2}, x$ and $y>01$. Then the game is:

\begin{tabular}{|c|c|c|}
\hline \multirow{4}{*}{ (1) } & (2) & \\
\hline & $\mathrm{H}$ & $\mathrm{L}$ \\
\hline & $\mathrm{a}_{1}$ & 0 \\
\hline & 0 & $\mathrm{a}_{2}$ \\
\hline
\end{tabular}

\footnotetext{
${ }^{1}$ See annexe 1.
} 
The solution of the model gives us four configurations according to the structure of the payoff matrix. These configurations depend on only two factors:

a)

$\mathrm{a}_{1}=(\mathrm{a}-\mathrm{g})=\mathrm{x}\left(\mathrm{a}^{\prime}-\mathrm{g}^{\prime}\right)$ or strategic premium of alignment on high quality: it represents the pay-off difference between $h$ and 1 when the other players choose $\mathrm{H}$.

b) $\quad a_{2}=(d-b)=y\left(d^{\prime}-b^{\prime}\right)$ or strategic premium of alignment on low quality; it represents the pay-off difference between $\mathrm{h}$ and 1 when the other players choose L.

During the seventeenth, eighteenth, and nineteenth centuries, each wine variety constituted a specific and autonomous market, with its specific institutions, traders, rules, and mechanisms of price formation. Producers could be assumed homogeneous: ${ }^{2}$ the differences between them were not significant and outcomes depended on the same determinants (type of vine, weather, soil, and so on). Then, the diverse configurations involve different issues with very diverse equilibria and evolutionary stable strategies. Consider the four possible configurations:

Configuration $\mathrm{I}$ : $\mathrm{a} 1<0$ and $\mathrm{a} 2>0,1$ is the best reply to $\mathrm{H}$ and to $\mathrm{L}$. There is a unique evolutionary equilibrium (1,L), a low equilibrium; all the producers, through learning and the observation of payoffs, use the strategy of low quality. Whatever the initial situation or shift induced by any stochastic shock, from every point corresponding to a quality between low and high, producers move to the attractor, the low quality equilibrium.

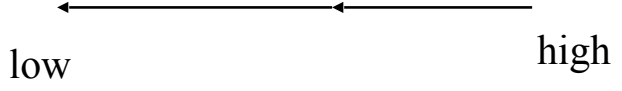

Configuration II: a1 $>0$ and $\mathrm{a} 2>0, \mathrm{~h}$ is the best reply to $\mathrm{H}$ and 1 is the best reply to $\mathrm{L}$, There are two evolutionary equilibria, a high one $(\mathrm{h}, \mathrm{H})$ and a low one $(1, \mathrm{~L})$; all the players choosing at the same time the same strategy; each equilibrium has a basin of attraction separated in $\lambda$ (with $\lambda=a_{2} / a_{1}+a_{2}$ ), and the quality is randomly determined. The probability of a low equilibrium is $\lambda$ and of a high one, it is $1-\lambda$.

\footnotetext{
2 When heterogeneity is dominant, as we will further examine (Section 6), some differences in the dialectic of choices will intervene.
} 


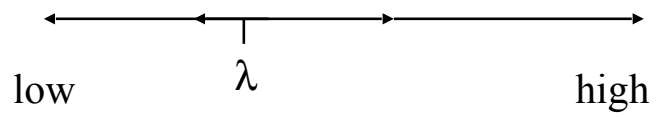

Configuration III: $\mathrm{a} 1>0$ and $\mathrm{a} 2<0, \mathrm{~h}$ is the best reply to $\mathrm{H}$ and to $\mathrm{L}$. We have a unique evolutionary equilibrium $(\mathrm{h}, \mathrm{H})$, a high equilibrium; everybody is playing the pure high quality strategy.

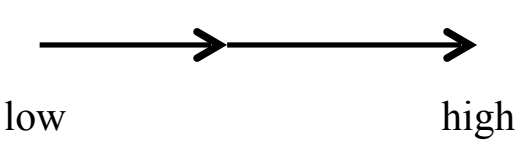

Configuration IV: $\mathrm{a} 1<0$ and $\mathrm{a} 2<0,1$ is the best reply to $\mathrm{H}$ and $\mathrm{h}$ to $\mathrm{L}$. The unique solution when producers are homogeneous implies intermediate quality $\lambda \mathrm{h}+(1-\lambda) 1$ (with $\lambda=\mathrm{a} 2$ / a1+a2). This equilibrium is asymptotically stable.

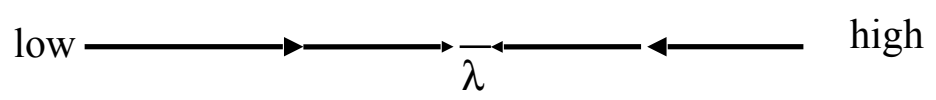

In the case of heterogeneity (the population is separated in two subpopulations), the results are the same except in the configurations IV. We consider this case later (Section 5). 


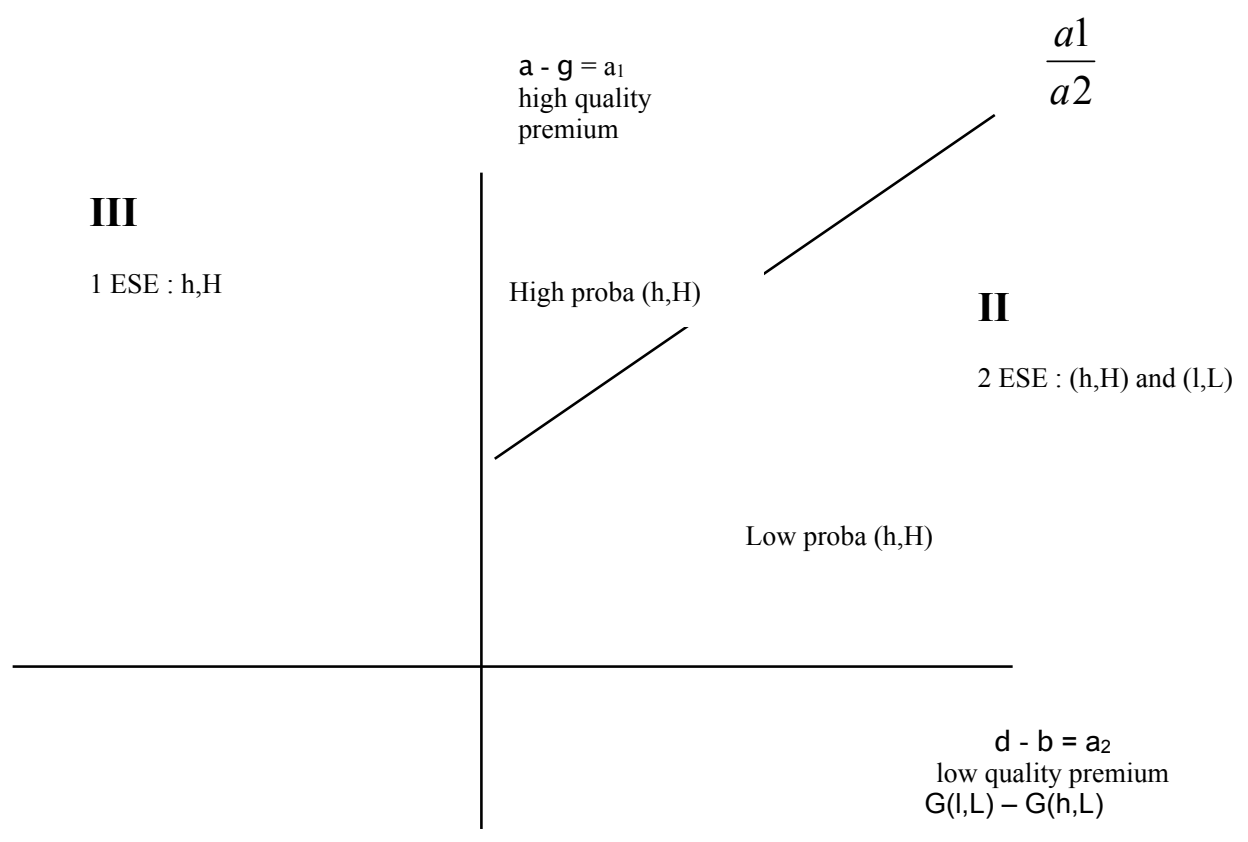

IV

1 ESE : $[\lambda h,(1-\lambda)]]$

1 ESE : $1, \mathrm{~L}$

We may use this general model to explain the diverse evolutionary paths of the wine markets by considering the values of $\mathrm{a}_{1}$ and $\mathrm{a}_{2}$ and understanding the economic conditions they express.

\section{The connoisseurs' markets (configurations III and path 1).}

In configuration III the functioning of the market spontaneously produces an evolutionarily stable high quality equilibrium.

According to condition $1\left(a_{1}>0\right)$, the premium on high quality is positive and $h$ is the best reply to $\mathrm{H}=\mathrm{BR}_{1}(\mathrm{H})$. The conditions of information allow discrimination between producers, for instance through trade marks, and authorize producers to sell at a high quality, with a supplementary cost and a higher price. 
According to condition $2\left(\mathrm{a}_{2}<0\right)$ the premium of alignment on low quality is negative: what is possible if the seller signals, through the trade mark, the specificity of low quality.

This market is perfectly informed. The game has a unique (ESE) equilibrium in dominant strategies $[\mathrm{h}, \mathrm{H}]$, with asymptotic stability. Everyone is interested in selling high quality products and reaping higher the profits. The perfection of information permits this outcome.

This configuration may be seen to represent some vineyards in the aristocratic age, ${ }^{3}$ as in the case of the famous Bordeaux 'grands crus'. Information can be considered (near) perfect as a result of the institutional characteristics of the aristocratic markets for some wine varieties:

- When a variety is produced by one producer or by a few producers, consumers can know the characteristics (particularly the quality) of each output and distinguish them according to the name of the producers or of the soils (for instance, Chateau Latour).

$\circ$ Within the aristocratic area, the knowledge concerning wines is maintained and diffused by education and culture; as for creative products (Caves, 2000), discussions about wines do not bear transaction costs but rather produce amenities.

- Knowledge of wines is a means of competition among the members of the aristocracy, according to the logic of the 'société de Cour' (Elias, 1973).

- Each market is narrow and includes few producers.

$\circ$ Ceremonies and feasts are an occasion to taste wines and to discuss wine among connoisseurs.

The 'etiquette' of such markets hinges on the names of the soil and the producer. It is closer to the griffe of the Grand Couturier than to a market trademark. Configuration III may illustrate the development of the famous wines of Burgundy and Bordeaux, with path 1 (see Annex 2) involving the reproduction of high quality standards. But these conditions are observed for famous wines only. Given their qualities and prices, connoisseurs are especially interested in their appreciation. In contrast, with many middle range wines, the related costs of information and transaction are much higher.

\footnotetext{
${ }^{3}$ In the section 7 we define more precisely the idea of an aristocratic age.
} 


\section{Low quality markets (configurations I and II and path 2)}

Configuration I corresponds to $\mathrm{a}_{1}<0$ and $\mathrm{a}_{2}>0$. The first condition expresses that the low quality strategy is the best reply to the high quality strategy of other players. It may be the consequence of characteristics of natural assets; where soils and weathers favour high quantity rather than high quality strategies. But it is also a highly feasible outcome, even for good vineyards that could produce a high quality wine. On a market with high costs of information and numerous producers, the general quality of wine is difficult to discern and price is not a reliable indicator (Gergaud, 2000). Consumers will not be able to discriminate easily between high and low quality wines. Whatever their quality, all products will be sold at the same price. For the producer, the low quality strategy saves the extra cost of producing high quality wines.

The second condition $\mathrm{a}_{2}>0$ means that the cost of maintaining high quality in response to low quality is positive. It may be that the seller is unable to maintain credibility because the costs of information are high. A prisoners' dilemma arises, with a sub-optimal equilibrium in dominant strategies, $(1, \mathrm{~L})$, the only evolutionarily stable equilibrium (ESE), and with L the only evolutionarily stable strategy (ESS). ${ }^{4}$ Imperfection of information induces opportunistic strategies that undermine quality. The unique equilibrium is a low quality outcome; as they observe payoffs and learn, all producers gravitate to a low quality strategy. Unless the institutional conditions of information or production change, the market is unable to escape from this low quality equilibrium.

There is another reason for the reproduction of a low quality. History shows that in situations of crisis (either very large or very thin wine harvests) opportunistic strategies become more and more attractive, even on high quality segments. The temptation to cheat is strong, particularly the temptation to be among the first to cheat, as the rewards are greater with fewer cheats. If cheating becomes institutionalized as a strategy, then it destroys the possibility of anything else but a low quality outcome.

\footnotetext{
${ }^{4}$ A standard replication mechanism (Weibull, 1995, chs. 3 and 5) leads to dynamics: $\mathrm{dh} / \mathrm{dt}=\mathrm{h}(1-\mathrm{h})\left[\mathrm{a}_{1} \mathrm{~h}-\mathrm{a}_{2}(1-\mathrm{h})\right]$, then $\mathrm{dh} /$ $\mathrm{dt}$ is always $<0$ and as the actors are homogenous we join, from every point, the attractor L.
} 
In configuration II, $\mathrm{a}_{1}>0$ and $\mathrm{a}_{2}>0$ and quality strategies are random. The two evolutionarily stable equilibrium are: E1 (h,H) and E2 (1,L), each one having a basin of attraction contiguous and separate in $\lambda=a_{2} / a_{1}+a_{2}$.

Condition $\mathrm{a}_{1}>0$ implies that the best reply to $\mathrm{H}$ is $\mathrm{h}$. If sellers can be discriminated, for instance through trademarks, they perceive that it would be better, when competitors sell high quality wines, to make the same strategic choice, to avoid elimination and to receive the higher profits attached to high quality. Condition $\mathrm{a}_{2}>0$ implies that the best reply to $\mathrm{L}$ is 1 . Quality cost remains positive, as in the former configuration. The sale by competitors of low quality products creates a negative externality on quality. Quality is only profitable if it is collectively played. That corresponds to a configuration in which producers have a name but without credible segmentation between high and low quality producers. A producer cannot risk maintaining high quality when faced with low quality wines that make consumers suspicious. He cannot reverse the situation by himself. In such circumstances, trademarks are insufficient to save good producers when others play bad quality. Negative externalities are stronger than positive ones. Hence, quality is unpredictable, evolving from a high to a low level, according to stochastic shocks and conjunctural conditions. A high quality wine cannot be securely organized in these circumstances. If there is no change in the conditions of the game, competitive evolution takes the producers out of the aristocratic segments of the market and confines all producers in low quality segments. This is path 2 with popular market and quantity strategies.

\section{The institutional solution of PDO (configurations I and II, path 3)}

In configurations I and II, the spontaneous outcome is low quality. Nevertheless, an institutionally organized market, such as the PDO system, may avoid this by developing a quality policy. The PDO has two facets. On the one hand, it is a means of informing consumers of existing quality. On the other hand, it is a means of developing and improving a high and stable quality standard. The institutional solution of a geographic indication of provenance emerged in Champagne, which is a region involving numerous producers of an elaborate wine. The dependence on a particular soil was not as tight as in the Bordeaux or the 
Burgundy regions. Variations in soil offer opportunities for opportunism, where some producers exploit the regional appellation while using low-quality soils. Concerned about their public reputation and capable of a long-term vision, the famous Maisons de Champagne created the AOC system, involving a regulatory mechanism to inhibit opportunistic strategies. ${ }^{5}$ This institution can transform a low or unstable quality market into a high quality market. It can create within a low quality market a new high quality segment. It is also used to guarantee the reproduction of quality on a high quality market, sustaining a necessary commitment to quality in periods of difficulty, when the preoccupations of the short term might otherwise dominate those of the long term.

Before the nineteenth century, Champagne wine was an ill-assorted collection of varieties and qualities. In the 1840-1870 period, two events occurred: there was an increase in demand for high-quality Champagne, mainly from the European Courts and from the aristocracy; and there was a concurrent improvement in possible quantity and quality due to decisive technical innovations. The increase in demand led local traders to specialize in Champagne and to the development of sparkling wines (instead of 'tranquille' Champagne wines). The vine growers inside the production area were encouraged to develop grape monoproduction for sparkling Champagne, ${ }^{6}$ and this along with the strategy of high quality limited variations among local vintages. ${ }^{7}$ Interests within each category (mainly the vine growers and the traders) were thus unified. The exporting traders, who first chose quality, increased their economic power and their regional leadership. They were in a position to impose their strategy of high quality. They defined the industrial development path around a quality policy and AOC designation, and imposed it as an expression of the global interest in Champagne. The 'defrauder-traders' (those who sold as champagne a wine coming from other areas or other grapes) lost out in the game and gave up their low quality strategy for a high quality strategy. Institutional arrangements were used to enforce this alignment. Vine growers had an incentive to regroup and to accept an economic agreement with the trade. The law was

\footnotetext{
5 For a more developed analysis of this historical process, see Barrère, 2000 and Barbier, $1986 .$.

${ }^{6}$ A separation was made between producers of grapes for Champagne and producers of other grapes and other wines, with a tendency for the absorption of the latter into the first group, along with the increasing relative profitability of Champagne and its grapes.

${ }^{7}$ At the end of the seventeenth century, the price of wine in Asfeld in the Ardennes, included in the category of the Champagne wines, was as low as between 10 and 14 livres the 'pièce' against 500 to 600 livres for Sillery wine (Le Champagne, 2000, p.69).
} 
used to develop institutional regroupings. Accordingly, the recognition of designation extended and crowned the strategy of the trade from the last quarter of nineteenth century, especially since judicial actions from 1880 to exclude 'foreigners' (to the region) from the Champagne market.

The AOC legislation followed the great Champagne crisis in the decade from 1910. This crisis encouraged the emergence of collective forms of organization and a political lobby. ${ }^{8}$ These institutions reduced the costs of organizing coalitions and induced new forms of management. The crisis eventually polarized the producers around positions common to each camp, thereby enabling unified and concerted action. E.Bin, the leader of the first vine growers' trade-union, used to tell his companions: 'Do as the merchants - ... Alone you are nothing and you will never be anything; grouped, you will be everything.' When the price of grapes collapsed, mainly because the merchants had considerably increased their wine purchases external to the region, the vine growers of Damery regrouped themselves to struggle against low prices. In response, the merchants decided to boycott the Damery grape producers. In retaliation, the vine growers set fire to the merchants' warehouses, occupied city halls, and organized demonstrations. In 1911, the government had to send in 12,000 soldiers to pacify the situation.

However, the revolt of 1911 was a turning point. During the confrontation, common interests were established, eventually creating the possibility of dialogue and compromise. The struggle of the vine growers was considered not as a struggle against merchants in general but against the 'defrauder traders'. Actors external to the confrontation, with their own interests, also promoted compromises; for example, national and regional political authorities imposed a 1911 law that prevented wine imports from other regions.

The occupation of the vineyards by troops was pivotal in the search for a compromise. The cost of inaction had reached its highest level. The search for solutions by each camp had become urgent and the cost more bearable! The cost of a coalition was lowered because the issue was taken up by administrative and political personnel (the prefect of the Marne played an extremely active role in the search for compromise solutions).

\footnotetext{
8 In the nineteenth century crisis caused by the phylloxera infection, vine growers lobbied politically and obtained chemical products at reduced prices, financial support to replant vines, and collective guarantees for the banks.
} 
To obtain the benefit of an AOC, wines have to conform to a certification process, founded on qualitative criteria. The AOC system eliminates low quality strategies and imposes high quality through specifications: lists of authorized types of vines, methods of vine cutting, maximum quantities, maximal quantity of grape per hectare, a definition of a minimal alcoholometry title, standards of pressing and grape delivery, procedures for wine making and conservation, delimitation of the protected production area, and so on.

Our model can be used to explain the working of the AOC regulation. It is efficient in configurations I and II where bad equilibria are possible because $\mathrm{a}_{2}$ is positive, that is to say when the strategic premium of alignment on low quality is positive, 1 being the best reply to L. The problem is to neutralize or to reverse this condition.

In some cases, as in the Champagne case, the AOC imposes on everybody a high quality by forbidding production of low quality through technical specifications of production; it excludes configurations I and II and directly leads the market to configuration III, with high quality. The pure strategies 1 and L become 'taboo' strategies and are excluded.

In other cases, the AOC intervenes in the functioning of the market:

In configuration $\mathrm{I}, \mathrm{a}_{1}<0$ and $\mathrm{a}_{2}>0$. The AOC regulation raises $\mathrm{a}_{1}\left[\mathrm{G}_{1}(\mathrm{~h}, \mathrm{H})-\right.$ $\left.\mathrm{G}_{1}(1, \mathrm{H})\right]$ because a seller of bad quality can loose the right to denomination. Simultaneously a $\left[\mathrm{G}_{1}(\mathrm{~h}, \mathrm{~L})-\mathrm{G}_{1}(1, \mathrm{~L})\right]$ becomes negative as far as the AOC allows, signalling good producers.

In configurations II, the probability of optimal equilibrium $(h, H)$ is an increasing function of $\mathrm{a}_{1}$ and decreasing function of $\mathrm{a}_{2} \cdot{ }^{9}$ For $\mathrm{a}_{1}$, the premium of alignment on high quality (i.e. profit surplus of producing high quality instead of low when the others sell high quality), two opposite effects exist. The first is the reputation effect, which tends to increase $\mathrm{a}_{1}$. The AOC consolidates the reputation of the sellers of high quality. The second is an opportunism effect, low quality producers can exploit the good image of the high quality producers without paying the production cost. The AOC, however, prohibits bad quality because of the threat of loosing the appellation. For $a_{2}$, the premium of alignment on low quality tends to diminish in a market with more and more identifiable producers; the AOC acts to increase discrimination between producers and to increase the correlation between

$91-\lambda=a_{1} / a_{2}+a_{1}$ i.e $1 / 1-\lambda=1+a_{2} / a_{1}$. 
revenues and real quality. In markets with many small producers, the AOC strategy ensures their reputation and development. So, the AOC increases the probability $(1-\lambda)$ of a high quality equilibrium $(\mathrm{h}, \mathrm{H})$. However, risks of low quality and of regression persist because the selection of equilibrium depends, ceteris paribus, on the initial choice ${ }^{10}$ and is sensitive to shocks. Quality thus remains uncertain; any exogenous shock may cause a switch to the other equilibrium. A low equilibrium may persist if the management of the AOC is too weak and alternative mechanisms for maintaining high quality are absent.

\section{The complex configuration IV and its diverse connected paths}

According to condition $1\left(\mathrm{a}_{1}<0\right)$, as in configuration 1 , and in contrast to configuration III, the best response to $\mathrm{H}$ is 1 . This may happen if the opportunism effect is stronger than the individual reputation effect. Condition $2\left(a_{2}<0\right)$ means that the cost of quality (involving a reply to low quality by the maintenance of high quality) decreases so strongly that it becomes negative, which is possible if the seller is able to signal its specificity. This depends on the information on quality acquired through experience, the information given by word of mouth by connoisseurs, the information suggested by the type of soil (the 'griffe') or by the trademark, or the information given by the experts (guides).

If we interpret these as 'information conditions', they seem to be compatible only in rare circumstances. They tend to be contradictory, in that they imply, simultaneously, that information signals give sufficiently good information to satisfy condition 2 and sufficiently bad information to satisfy condition 1 . Hence, the situation is more linked to the preferences of the consumers.

On the supply side, two situations are to be distinguished. Producers may be homogeneous, in that they make similar choices when presented with the same opportunities. Alternatively, producers may be heterogeneous (random shocks or mutations may increase the diversity among producers) and make different choices in the same situations. Evolutionary game theory shows that games work differently depending on whether players are homogeneous or heterogenous.

\footnotetext{
10 An initial situation, on the left of $\lambda\left[a_{2} / a_{1}+a_{2}\right]$ corresponds to $h=a_{2} / a_{1}+a_{2}-\varepsilon$; then $G(H)=a_{1} a_{2} / a_{1}+a_{2}-a_{1} \varepsilon<G(L)=a_{1} a_{2} /$ $a_{1}+a_{2}+a_{2} \varepsilon$ and one goes to $L$; conversely, on the right of $\lambda, G(H)=a_{1} a_{2} / a_{1}+a_{2}+a_{1} \varepsilon>G(L)=a_{1} a_{2} / a_{1}+a_{2}-a_{2} \varepsilon$ and one goes to H.
} 


\section{Homogeneous players}

The unique evolutionary stable equilibrium yields a $\lambda \mathrm{h}+(1-\lambda) 1$ quality level. There are two possibilities. The first one is that producers supply the intermediate level of quality that consumers demand. As producers are similar, they all offer wine of intermediate quality. Is the market mechanism able to adjust to this level of quality? If the quality of the product is higher, $\mathrm{a}_{1}$ (which is negative) increases its absolute value and $\mathrm{a}_{2}$ (also negative) decreases its absolute value, then $\lambda$ and the supplied quality diminishes. If the quality of the product is lower, $\mathrm{a}_{1}$ (which is negative) decreases its absolute value and $\mathrm{a}_{2}$ (also negative) increases its absolute value, then $\lambda$ and the quality increases. From an economic point of view this process implies that information about preferences is to be transferred through the price mechanism and that producers can respond in time. Path 4 represents this market adjustment. This situation may involve aristocratic segments that decrease in quality or popular segments that increase in quality. But economic circumstances may not correspond to the mathematical conditions of the game. Path 2 shows producers on the high quality segments that do not follow consumer wishes for a lower quality because they may lose their reputation and be forced towards popular segments. On path 3 the AOC adjusts and guarantees an adapted level of quality.

Another possibility is that all producers supply a fraction $\lambda / 1$ of high quality wine and supply a fraction $(1-\lambda) / 1$ of low quality wine. The condition $\mathrm{a}_{1}, \mathrm{a}_{2}<0$ implies that $\mathrm{G}(\mathrm{h}, \mathrm{H})$ and $\mathrm{G}(1, \mathrm{~L})<\mathrm{G}(1, \mathrm{H})$ and $\mathrm{G}(\mathrm{h}, \mathrm{L})$; i.e a combination of identical quality strategies gives less than a combination of different ones. That may represent a situation in which the coexistence of two qualities, now distinguishable, $\mathrm{H}$ and $\mathrm{L}$, enlarges the potential market, according to differences in willingness to pay. Instead of strong competition on a thin market, as in the $(\mathrm{H}, \mathrm{H})$ and also in the $(\mathrm{L}, \mathrm{L})$ situations, complementary supplies may satisfy all the consumers and permit the competing pressures to relax. It still may involve aristocratic or popular segments.

In the aristocratic segment, a new differentiation works and we have path 5, involving 'second wines'. If the 'first' wine has a famous name and is a symbol of aristocratic quality, then the second one takes advantage of this quality reputation, even if the second one is lower and 
satisfies a new type of demand. Economic conditions may hamper market regulation. Some producers can offer a quality inferior to the low quality required by consumers, lose their reputation and be demoted from the aristocratic market (path 2). The management of the AOC system, as previously, can help to adjust supply to demand (path 3). Finally, aristocratic markets can mix production of intermediate quality and production of differentiation and evolve according a path 6 .

In the popular segments, where the vineyards share similar conditions of production, empirical observation reveals the evolution of differentiated markets. At first, they produce similar wines but, with the development of social differentiation, they produce differentiated wines. There is simultaneously demand for medium and for low quality products. This implies that each quality can be known and distinguished from the others. On a large and popular market, information is communicated through private quality labels, based on the reputation of the trademarks. For instance, in France in the 1950s, the most important trademarks offered green, blue and red caps to distinguish bottles according to quality, related to their alcoholic strength. The differentiation was reinforced by the diversity of the vineyards. The popular market was not a unified market but a market of 'mosaics' with a high number of varieties, including numerous local varieties. In France the Languedoc wine market is not strictly the same as the market for Loire, Cahors, or Alsace wines; in Italy, Sardinian or Sicilian wines are sold through channels different from those of Venetian wines. The phenomenon is the converse of that described by path 5 in the aristocratic market. In aristocratic market, quality declines from a previously high level, in the popular market it is raised to a medium level.

\section{Heterogeneous players}

If the population of producers consists of two distinct components, then the game gives us two opposite and asymmetric equilibria, $(\mathrm{h}, \mathrm{L})$ and $(\mathrm{l}, \mathrm{H})$. This may correspond to a market with two stable levels of quality, one high and one low, and a path similar to the previous path 5. As before, economic conditions may hamper the working of market regulation. Some producers can offer a quality inferior to the low quality required by consumers and be demoted from aristocratic market (path 2); the AOC system can still be an appropriate way to adjust supply to demand (path 3 ). 


\section{The PDO system in the age of globalisation}

How do we explain the previously strong historical segmentation of wine markets between 'aristocratic' wines and 'popular' wines? At its root there was the extreme social segmentation between the elite and the people, involving two distinct types of consumer. Luxury goods were consumed by the elite only and beyond the reach of other social groups.

Today, however, wine consumption and production are changing. There is an integration and globalisation of different wine markets (Anderson, 2004). World wine markets are moving from an aristocratic paradigm of wine consumption and its corresponding market organization, to a mass market paradigm with new market configurations. In this new luxury market paradigm a great number of people can buy luxury goods. Simultaneously, many producers can make quality wine. These factors create new conditions for the PDO.

PDO had two different and related functions: to establish a minimum level of quality by constraining producers, and to guarantee consumers this level of quality. It is simultaneously a standard of production and a system of information (Stanziani, 2004; Torre, 2002). It has been a very successful means of organisation of wine markets under the old conditions, but how can a PDO system work under the new conditions of globalisation and mass luxury consumption? We consider our previous results in the light of these recent changes:

1. In the former configuration III, PDO was unnecessary; the names of the producer and of the soil established a strong reputation. Consider the new market with new consumers, some of whom have little knowledge of wines. PDO may introduce confusion between famous 'griffe' and standard PDO. For instance, Petrus has no interest to be considered as a same type of wine as a standard 'Bordeaux appellation contrôlée', Romanée-Conti to be compared with a standard 'Bourgogne wine', or Krüg and Roederer with a generic Champagne. Accordingly, famous high quality producers seek to enlarge their differences from the PDO wines.

2. In the former configurations I and II, PDO was useful. Its efficiency derives from its ability to manage the main problem with these configurations, that of opportunism. In configuration IV PDO was also used to fix the minimum level of quality for an 
intermediate quality wine. But PDO is now a victim of its success! Many vineyards, in the European countries (the most spectacular changes occurred in Spain and Italy, with a high growth in quality) adopted the PDO system. Consequently, competition and segmentation is less between a few PDO wines and a lot of other wines, but more between a lot of PDO denominations and a few low quality wines. Hence, the PDO system yields less profit and loses its specificity. A second reason is that a PDO is a strong signal for a wine that obtains a PDO for the first time (or obtains a more prestigious PDO, such as a move from a Bordeaux denomination to a Medoc denomination), but when a wine is already protected it is difficult to convince consumers that a strengthening of the PDO leads automatically to an improvement of the wine quality. PDO works in a qualitative rather than a quantitative manner. In a context of world overproduction, producers seek safety in differentiating their products, but PDO declines in efficiency. A last reason is that in situations of local overproduction (as in the Bordeaux case) the collective organisation of PDO is not always able to check quality; opportunism may occur and the collective reputation is undermined.

3. In relatively new areas of wine mass production (Chile, Australia, California, South Africa, etc.) production conditions are very different. Instead of wines differentiated by soil or locality they produce wines characterized by the type of vine (Merlot, Chardonnay, Gamay, etc.). Consequently, PDO based on soil characteristics becomes irrelevant and producers differentiate their products through trademarks and private denominations.

PDO is an historic institution. It emerged where it allowed particular wines to join aristocratic segments with connoisseur information systems to constitute quality wine markets. Today it has to be adapted to the new circumstances of a mass global market and related information conditions. Institutions maintain their efficiency only through their evolution. 


\section{Annexe 1}

The levels of the payoffs can be different but their structure has to be the same. If the order between $\alpha^{\prime}, \beta^{\prime}, \gamma^{\prime}, \delta^{\prime}$ is always the same as the order between $\alpha, \beta, \gamma, \delta$, we can transform the first game in the next ones and, with $a_{1}=a-g, a_{2}=d-b, b_{1}=$ $a^{\prime}-g^{\prime}, b_{2}=d^{\prime}-b^{\prime}, x=a_{1} / b_{1}, y=a_{2} / b_{2}$.

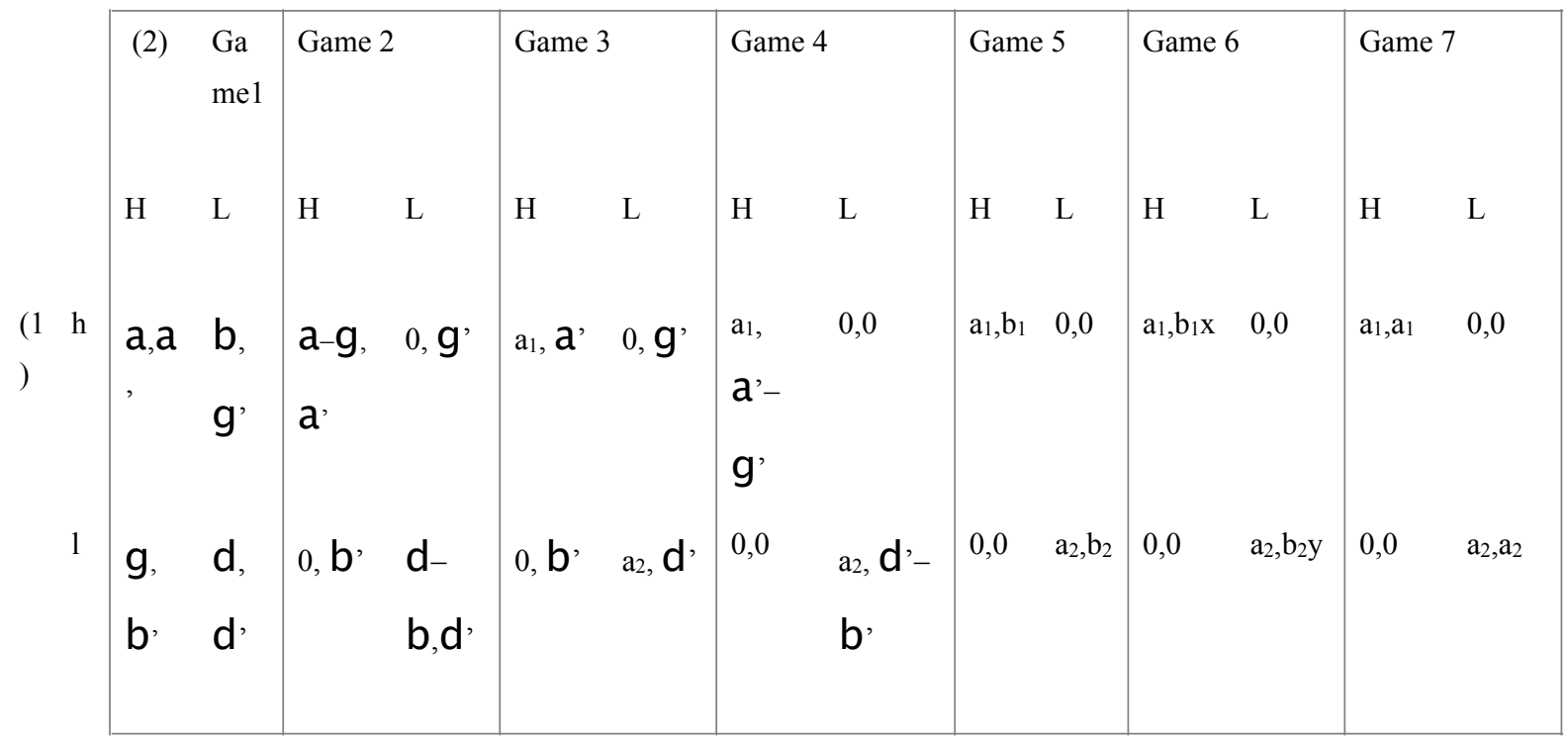

In symmetric game 7 the equilibria are not the same as in the first one, because of transformations, but the configuration of equilibria (number, type and so on) is the same. When $\mathrm{a}_{1}=\mathrm{a}-\mathrm{g}$ is positive (negative), also $\mathrm{b}_{1}=\mathrm{a}^{\prime}-\mathrm{g}^{\prime}$ is positive (negative), that is to say $\mathrm{h}$ is best reply to $\mathrm{H}$ (respectively $\mathrm{l}$ ), for all the players; when $\mathrm{a}_{2}=\mathrm{d}-\mathrm{b}$ is positive (negative), also $b_{2}=d^{\prime}-b^{\prime}$ is positive (negative), that is to say 1 (respectively $h$ ) is best reply to $L$, for all the players. So, $x=a_{1} / b_{1}, y=a_{2} / b_{2}>0$, and no sign modification is done from game 1 to game 7, no equilibrium configuration's modification is done. As we focuses on the configuration, the transformation is allowed. 
Annexe 2

\begin{tabular}{|c|c|c|c|}
\hline & \multicolumn{2}{|l|}{ A2 $<0 ; \mathrm{h}=$ Best Reply (L) } & $\mathrm{a} 2>0 ; \mathrm{l}=\mathrm{BR}(\mathrm{L})$ \\
\hline $\begin{array}{l}\text { a } 1>0 ; \\
\mathrm{h}=\mathrm{BR}(\mathrm{H})\end{array}$ & \multicolumn{2}{|c|}{$\begin{array}{l}\text { Configuration III } \\
1 \mathrm{EES}=(\mathrm{h}, \mathrm{H}) \\
\text { Path } 1 \text { reproduction or raising of a high quality } \\
\text { Aristocratic markets ('famous Bordeaux') }\end{array}$} & $\begin{array}{l}\text { Configuration II } \\
2 \text { EES= }(1, \mathrm{~L}) \text { and }(\mathrm{h}, \mathrm{H}) \\
\text { Path } 2 \text { popular markets, quantity and low } \\
\text { quality strategies ('vins de pays') } \\
\text { Path } 3 \text { AOC }\end{array}$ \\
\hline $\begin{array}{l}\text { a } 1<0 ; \\
\mathrm{l}=\mathrm{BR}(\mathrm{H})\end{array}$ & $\begin{array}{l}\text { Configuration IV } \\
\text { Homogeneous producers } \\
1 \mathrm{EES}=\lambda \mathrm{h}+(1-\lambda) 1 \\
\text { Paths } 2 \text { low quality } \\
\text { Paths } 3 \text { AOC } \\
\text { Path } 4 \lambda \text { quality } \\
\text { Path } 5 \text { differentiation; } \lambda \mathrm{h} \text { and } \\
(1-\lambda) 1 \text { qualities } \\
\text { Path } 6 \text { differentiation; } h, 1 \text {, and } \\
\lambda \text { qualities }\end{array}$ & $\begin{array}{l}\text { Configuration IV } \\
\text { Heterogeneous producers } \\
2 \mathrm{EES}=(\mathrm{h}, \mathrm{L}) \text { and }(1, \mathrm{H}) \\
\text { Path } 2 \text { low quality } \\
\text { Path } 3 \text { AOC (Champagne) } \\
\text { Path } 5 \text { differentiation; } \lambda \mathrm{h} \\
\text { and }(1-\lambda) 1 \text { qualities }\end{array}$ & $\begin{array}{l}\text { Configuration I } \\
\text { EES= (1,L) } \\
\text { Path } 2 \text { low quality ('vin d'Algérie') } \\
\text { Path } 3 \text { AOC ('AOC Languedoc') }\end{array}$ \\
\hline
\end{tabular}




\section{REFERENCES}

Anderson, K 2004 (ed.) The World's Wine Markets. Globalization at Work, Edward Elgar.

Barbier, J.L 1986 « Contribution à l'étude des relations entre les professions et l'Etat. L'exemple du Comité inter-professionnel du vin de Champagne », Thèse pour le doctorat d'Etat en droit, Université de Reims, 1986.

Barrère, C. 2000 La construction d'un patrimoine juridique comme mode de construction d'un patrimoine économique: le cas du Champagne, in Revue française de droit rural, n. 288, décembre.

Caves, R. 2000 Creative Industries. Contracts between Art and Commerce, Cambridge (Mass.), Harvard University Press.

Elias, N. 1973, La civilisation des mœurs. Calmann-Lévy. édition Presses Pocket.

Gergaud, O. 2000 Fonctions de prix hédonistiques et information imparfaite: le rôle de la réputation sur le marché du vin de Champagne, Thèse pour le doctorat en sciences économiques, Université de Reims.

Hargreaves P.S, Varoufakis Y 1995 Game Theory: A Critical Introduction, London, Routledge.

Le Champagne, 3 siècles d'histoire. 2000, Stock.

Stanziani, A. 2004 Wine Reputation and Quality Controls: the Origin of the AOCs in 19th Century France in European Journal of Law and Economics, 18:149-167.

Torre, A. 2002 Les AOC sont-elles des clubs ? Réflexions sur les conditions de l'action collective localisée, entre coopération et règles formelles in Revue d'Economie Industrielle, $\mathrm{n}^{\circ} 100,3^{\circ}$ trim.

Weibull, J.G. 1996 Evolutionary Game Theory, Cambridge, MIT Press.

Weber, Max (1949) Max Weber on the Methodology of the Social Sciences, translated and edited by Edward A. Shils and Henry A. Finch (Glencoe, IL: Free Press). 